\title{
Preliminary Evaluation of Thulium Doped Fiber Laser in Pig Model of Liver Surgery
}

\author{
Maciej Janeczek (iD, ${ }^{1}$ Jacek Świderski $\left(\mathbb{D},{ }^{2}\right.$ Albert Czerski, ${ }^{3}$ Bogusława Żywicka, \\ Jolanta Bujok (D), ${ }^{3}$ Maria Szymonowicz, ${ }^{4}$ Ewa Bilewicz, ${ }^{1}$ Maciej Dobrzyński ${ }^{\mathbb{D}},{ }^{5}$ \\ Mariusz Korczyński, ${ }^{4,6}$ Aleksander Chrószcz, ${ }^{1}$ and Zbigniew Rybak ${ }^{4}$ \\ ${ }^{1}$ Department of Animal Physiology and Biostructure, Division of Anatomy, Wroclaw University of Environmental and Life Sciences, \\ Kożuchowska 1, 51-631 Wroclaw, Poland \\ ${ }^{2}$ Institute of Optoelectronics, Military University of Technology, Kaliskiego 2, 00-908 Warsaw, Poland \\ ${ }^{3}$ Department of Animal Physiology and Biostructure, Division of Animal Physiology, Wroclaw University of Environmental and \\ Life Sciences, C.K. Norwida 31, 50-375 Wroclaw, Poland \\ ${ }^{4}$ Department of Experimental Surgery and Biomaterial Research, Wroclaw Medical University, Bujwida Street 44, \\ 50-368 Wroclaw, Poland \\ ${ }^{5}$ Department of Conservative Dentistry and Pedodontics, Wroclaw Medical University, Krakowska 26, 50-425 Wroclaw, Poland \\ ${ }^{6}$ Department of Environment Hygiene and Animal Welfare, Wroclaw University of Environmental and Life Sciences, \\ Chelmonskiego 38c, 51-630 Wroclaw, Poland
}

Correspondence should be addressed to Jolanta Bujok; jolanta.bujok@upwr.edu.pl

Received 19 June 2018; Accepted 16 September 2018; Published 15 October 2018

Academic Editor: Christian Schwentner

Copyright (C) 2018 Maciej Janeczek et al. This is an open access article distributed under the Creative Commons Attribution License, which permits unrestricted use, distribution, and reproduction in any medium, provided the original work is properly cited.

Partial liver resection is a treatment of choice for liver tumors; the range of parenchyma excision varies from a small part of the tissue surrounding the neoplasm up to $70 \%$ of the organ. One of the major concerns during liver resection is blood loss. Thulium lasers which are characterized by the length of emission wave corresponding to a peak absorption of water create a new possibility of cutting tissues efficiently with minimal thermal damage and concurrently providing a good hemostasis control. The aim of our study was to evaluate an impact of liver transection with thulium doped fiber laser on an intraoperative bleeding and histopathological changes during postoperative period in swine model. Ten animals were subjected to open surgery partial liver resection and an incision of liver tissue with an all-fiber, diode-pumped, and continuous-wave $\mathrm{Tm}^{3+}$-doped fiber laser emitting $37.4 \mathrm{~W}$ of output power at $\sim 1.94 \mu \mathrm{m}$ wavelength. The macroscopic and histopathological evaluation was performed intraoperatively as well as 7 and 14 days after surgery. Macroscopically almost no bleeding was observed during surgery and no signs of bleeding were stated after 7 and 14 days. Histopathological analysis of the transection margin revealed a thermal damage area ranging in depth from $620.23 \pm$ $23.82 \mu \mathrm{m}$ on the day of surgery to $1817.70 \pm 211.98 \mu \mathrm{m}$ after 7 days. In the samples taken intraoperatively and after 7 days a superficial zone of carbonization was visibly separated from the deeper changes. After 14 days one $765.35 \mu \mathrm{m}$ deep zone characterized by a granulation was present. In conclusion, thulium doped fiber laser is efficacious in cutting with a narrow zone of thermal injury and provides a good hemostasis during liver transection, thus being a potential tool for oncotic liver surgery.

\section{Introduction}

Partial liver resection is the standard treatment for primary and secondary liver tumors. The two most common indications for liver resection are colorectal liver metastases and hepatocellular carcinomas, and the range of liver parenchyma resection varies from limited to the tissue surrounding the tumor to up to $70 \%$ of the organ $[1,2]$. Although the liver resection technique is being constantly improved and the perioperative complication rate markedly decreased, it still remains a demanding surgical procedure with significant mortality and morbidity [3]. One of the major concerns during liver surgery is blood loss, as it has been demonstrated to be one of the main predictors of perioperative 
complications and death [4]. Many novel interventional techniques are aimed at reducing blood loss during liver parenchyma transection and managing the cut surface [1]. Another objective is to perform liver tumor resections with safe tissue margins, while leaving as much tissue as possible, especially if the patient is suffering from liver cirrhosis. Excessive excision of the liver parenchyma in this case may result in an organ failure. Therefore, a device allowing great hemostatic control and precise cut with maximum sparing of the unaffected tissue would be of advantage in liver surgery.

Soon after Maiman in 1960 discovered the first rubybased working laser, many types of gaseous, liquid, and solid materials were found applicable in a laser technique [5]. Concurrently, first experiments on medical laser application begun and only a couple of years after Maiman's discovery, ruby laser was studied in ophthalmology leading to an extensive use of modern laser devices in this branch of medicine $[6,7]$. Currently, medical laser devices are widely used not only in ophthalmology, but also in laryngology, dermatology, urology, oncology, and surgery, and the number of procedures performed with lasers continually grows. Several types of lasers are used in soft tissue surgery, inter alia carbon dioxide $\left(\mathrm{CO}_{2}\right)$, neodymium-doped yttrium aluminum garnet (Nd:YAG), and diode lasers [8-12]. Thulium doped fiber (Tm:fiber) lasers with the wavelength close to $2000 \mathrm{~nm}$ which corresponds to peak absorption of water are potentially promising tools in surgery, characterized by high efficiency and minimal thermal damage of the surrounding tissues [13]. However, data on its applicability in liver surgery are sparse.

The aim of our study was to evaluate an impact of liver transection with all-fiber, diode-pumped, continuous-wave $\mathrm{Tm}^{3+}$-doped fiber laser on an intraoperative bleeding and histopathological changes during postoperative period in swine model.

\section{Materials and Methods}

2.1. Study Protocol and Animals. The experiment was approved by the Second Wroclaw Local Ethics Committee for Animal Experimentation (no. 50/2012) and performed in accordance with the standards established in the directive of the EU (2010/63/EU). 10 Polish Large White (WBP) female pigs aged 10 weeks were used in this study. The animals were obtained from a single farm (The National Research Institute of Animal Production, Experimental Station in Pawłowice, Poland) and acclimatized for 2 weeks before enrolling into one of two equal groups. In both experimental groups, the animals underwent partial hepatectomy of the right lateral lobe and incision of the liver parenchyma under general anesthesia. The excised fragments of tissue were assessed by histopathology (HP). After recovery from anesthesia, pigs were kept in the pens of a vivarium for 7 days (T1 group) or for 14 days (T2 group) and, after this period of time, were euthanized with intravenous pentobarbitone $(48-96 \mathrm{mg} / \mathrm{kg}$; Morbital $^{\circledR}$, Biowet Puławy, Poland) to obtain tissues for HP.

2.2. Laser Properties. The thulium laser used in the experiment was a prototype all-fiber, diode-pumped, and continuous-wave $\mathrm{Tm}^{3+}$-doped fiber laser. The laser was built with the use of a mode area single-mode thulium doped fiber. The silica core fiber $25 \mu \mathrm{m}$ in diameter (0.09 NA) placed in a $250 \mu \mathrm{m}$ octagonal clad fiber (0.46 NA) was pumped by one $793 \mathrm{~nm}$ laser diode with $200 \mu \mathrm{m}$ diameter (0.22 NA) pigtail fiber. Optical cavity of the laser consisted of two fiber Bragg gratings with the wavelength of $1940 \mathrm{~nm}$; the first was highly reflective and the second partially reflective and served as an output coupler fused with a passive transmitting fiber which ended with a high power FC/APC connector. A dichroic mirror at the output end was filtering the residual diode pump light and $1940 \mathrm{~nm}$ laser light. Tm:fiber laser was emitting $37.4 \mathrm{~W}$ of output power at $\sim 1.94 \mu \mathrm{m}$ wavelength. The device used in this study was constructed in the Institute of Optoelectronics, Military University of Technology (Warsaw, Poland), and its properties were described in detail by Michalska et al. [14].

2.3. Surgery and Visual Inspection. The animals were sedated with intramuscular (i.m.) injection of medetomidine $\left(0.1 \mathrm{mg} / \mathrm{kg}\right.$ body weight; Domitor ${ }^{\circledR}$, Orion Pharma, Poland) and butorphanol $\left(0.2 \mathrm{mg} / \mathrm{kg}\right.$ body weight; Butomidor ${ }^{\circledR}$, Richter Pharma AG, Austria) and were inserted a venous catheters into the auricular veins. Intravenous (i.v.) propofol bolus ( $4 \mathrm{mg} / \mathrm{kg}$; Scanofol ${ }^{\circledR}$, Scan Vet, Poland) was used to induce anesthesia in pigs, to allow their placement in the dorsal recumbent position and tracheal intubation. General anesthesia was maintained with $1.5 \%$ vol isoflurane. Analgesia was provided with an i.v. constant-rate infusion of fentanyl (50 $\mu \mathrm{g} / \mathrm{kg} / 10 \mathrm{~min}$, Polfa SA, Poland). Each animal received $500 \mathrm{ml}$ of Ringeri solution i.v. during the procedure. Surgical access was achieved by a midline incision through the linea alba. The right lateral lobe of the liver was identified visually and gently fixed with a sterile gauze. A partial incision and hepatectomy were performed in the $2 / 3$ distal part of the lobe, where the thickness of the tissue was approximately $2 \mathrm{~cm}$. The tip of the laser probe during cutting was kept at a distance of $2-5 \mathrm{~mm}$ from the tissue surface. The cut area was observed for $5 \mathrm{~min}$ to visualize bleeding or bile leakage. Afterwards, the abdominal cavity was closed in three layers. Before weaning form anesthesia the animals were given amoxicillinum (15 mg/kg body weight i.m.; Betamox LA ${ }^{\circledR}$, ScanVet, Poland) and metamizole $(30 \mathrm{mg} / \mathrm{kg}$ body weight i.m.; Biovetalgin ${ }^{\circledR}$, Biowet Drwalew, Poland) and placed in the pens. In the remaining period of the experiment (7 days and 14 days for $\mathrm{T} 1$ and $\mathrm{T} 2$ group, respectively) animals were observed for any signs of pain and their clinical status was evaluated. Pain was controlled with metamizole i.m. for 3 days after surgery.

2.4. Macroscopic Evaluation and Histopathology. After euthanasia, pigs were subjected to necropsy with a particular emphasis on the signs of bleeding or bile leakage from the site of resection, and the specimens from this part of the liver were collected for HP.

Specimens obtained either during surgery or necropsy were immediately fixed in $4 \%$ buffered formaldehyde for $72 \mathrm{~h}$ and then washed in running water for $24 \mathrm{~h}$. Before embedding in paraffin (Microm EC 350-1, Thermo Scientific, USA), specimens were dehydrated successively in $75 \%, 96 \%$, 
TABLE 1: Width of the microscopic changes in the right lateral lobe of the swine liver produced by the partial resection using a Tm:fiber laser.

\begin{tabular}{|c|c|c|c|}
\hline Specimen & $\begin{array}{c}\mathrm{T} 1 \text { and } \mathrm{T} 2 \\
\text { intraoperatively } \\
(\mathrm{n}=10)\end{array}$ & $\mathrm{T} 1(\mathrm{n}=5)$ & $\mathrm{T} 2(\mathrm{n}=5)$ \\
\hline Zone of superficial thermal damage in the liver tissue $[\mu \mathrm{m}]$ & $479.31 \pm 13.15$ & $291.60 \pm 18.28^{*}$ & - \\
\hline Total width of microscopic thermal changes in the liver tissue $[\mu \mathrm{m}]$ & $620.23 \pm 23.82$ & $1817.70 \pm 211.98^{*}$ & $765.35 \pm 55.94$ \\
\hline
\end{tabular}

T1 and T2: groups of animals undergoing euthanasia on days 7 and 14, respectively. Values are presented as mean \pm SD; n: number of animals. Values marked with $*$ differ significantly $(\mathrm{p}<0.05)$ from others in a row.

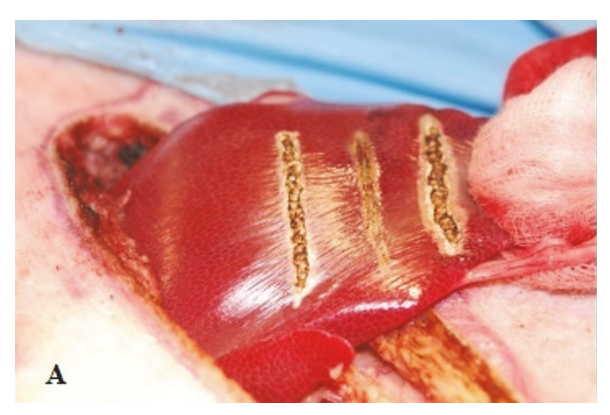

(a)

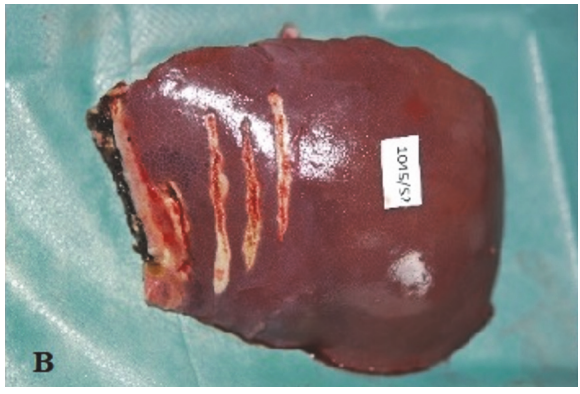

(b)

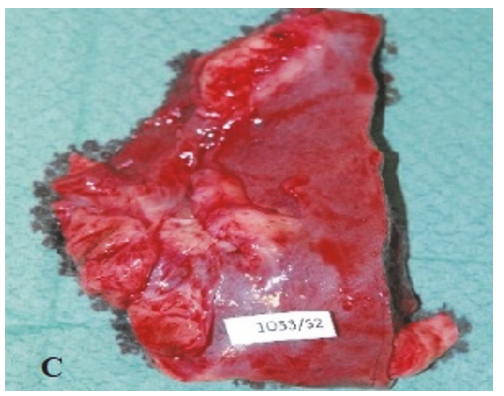

(c)

Figure 1: Macroscopic evaluation of right lateral liver lobe after thulium laser surgery. (a) Incision of the liver tissue with a thulium laser (first from the left), image taken intraoperatively; (b) macroscopic changes in pig liver on day 7; carbonization is visible in the resection wound; incomplete healing of the wound after incision (the first from the right); (c) a scar formation in the liver on day 14 (T2 group) after partial resection.

and $100 \%$ solutions of ethanol. Paraffin blocks with the liver samples were cut into $7 \mu \mathrm{m}$ sections using a sliding microtome (Zeiss Hyrax M25, Carl Zeiss Company, Germany) and were placed on glass slides. The sections were stained with hematoxylin and eosin (HE; Sigma-Aldrich, USA) according to the standard protocols [15]. Stained specimens were evaluated under the light microscope (Zeiss Axio Scope A1, Carl Zeiss Company, Germany). Histological measurements were made using Axio Vision 4.8 (Carl Zeiss MicroImaging $\mathrm{GmbH}$, Germany).

2.5. Statistics. Data are expressed as mean and standard deviation of average values from measurements made in specimens obtained from $n$ animals. Data were subjected to Student's $t$-test analysis using the Statistica for Windows ver. 10.0 software package (StatSoft, Tulsa, OK, USA). Differences between means were considered significant at values of $\mathrm{p}<$ 0.05 .

\section{Results}

3.1. Animals and Macroscopic Evaluation. All animals survived the surgical procedure without any complications. They remained in good clinical condition and had a good appetite until the end of the experiment and were euthanized after 7 or 14 days in $\mathrm{T} 1$ or $\mathrm{T} 2$ group, respectively.

Intraoperatively not any signs or minor signs of bleeding during 5 minutes after cutting the tissue with Tm:fiber laser were observed in the pigs from $\mathrm{T} 1$ and $\mathrm{T} 2$ groups. No bile leakage was observed. On the surface of the excision and incision margins a carbonization was present, which macroscopically formed a 1-2 mm deep zone in the liver lobe. After 7 days carbonization was still visible, while after 14 days only small foci of carbonization remained. No extravasated blood, clots, or any other signs suggesting delayed bleeding or bile leakage were present in T1 and T2 group. After 14 days adhesion of the liver with abdominal wall or neighboring organs at the site of cutting was visible. Tissue of the liver lobe apart from the incision line showed no macroscopic changes in any of the animals (Figure 1).

3.2. Histopathology. During HP evaluation of specimens taken intraoperatively and 7 days after surgery the superficial and deep zones of changed tissue were distinguished, whereas in T2 group both zones merged. The width of the thermally changed area and its microscopic appearance varied with time (Table 1, Figures 2-4).

The superficial zone of the microscopic changes in specimens collected intraoperatively was characterized by exudation and carbonization without extravasated erythrocytes. In the deeper zone of thermal damage morphologically altered lobules were present; however, hepatic cells themselves had a preserved structure and intact nuclei. This layer was clearly separated from the normal liver parenchyma (Figure 2).

In the samples from $\mathrm{T} 1$ group a superficial zone with carbonized tissue and exudative phase was still present; however, the width of this layer decreased significantly (Table 1). The deeper zone was characterized by the granulation tissue area with large number of small blood vessels with thin walls. In this area the proliferation phase with mesenchymal cells, hepatocytes, and fibroblasts was present. Deeper in this zone of thermal damage the necrotic foci surrounded by the 


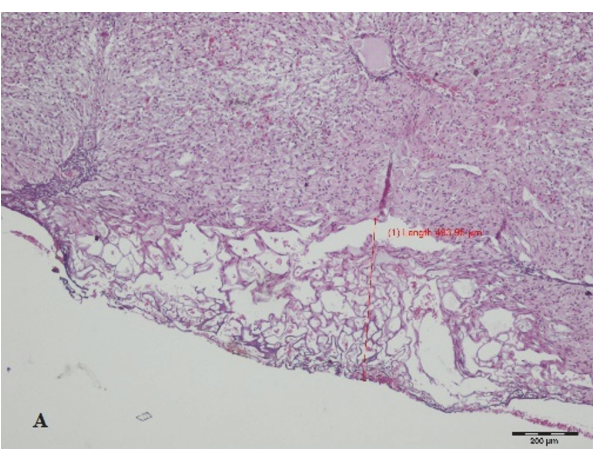

(a)

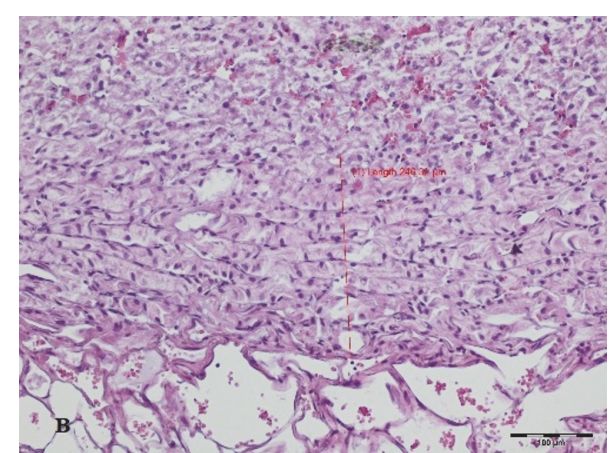

(b)

FIGURE 2: Histopathological evaluation of the fragment of the liver excised with thulium laser on day 0 (HE staining). (a) Magnification $\times 40$; (b) magnification $\times 100$.

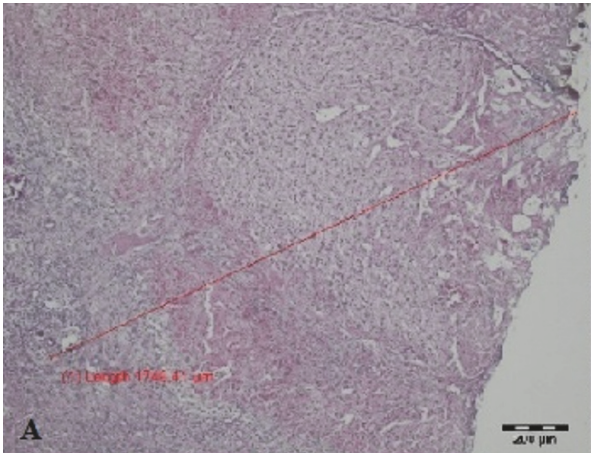

(a)

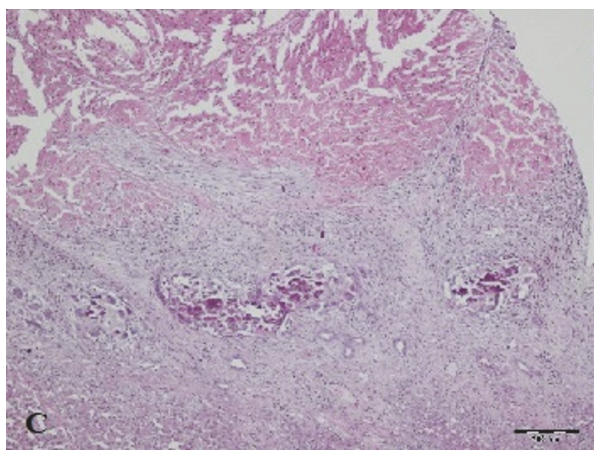

(c)

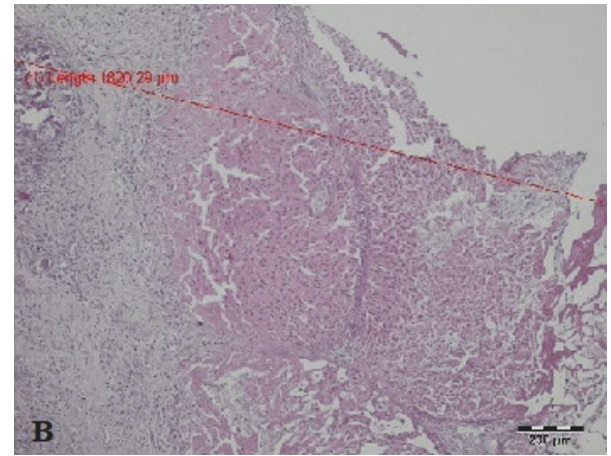

(b)

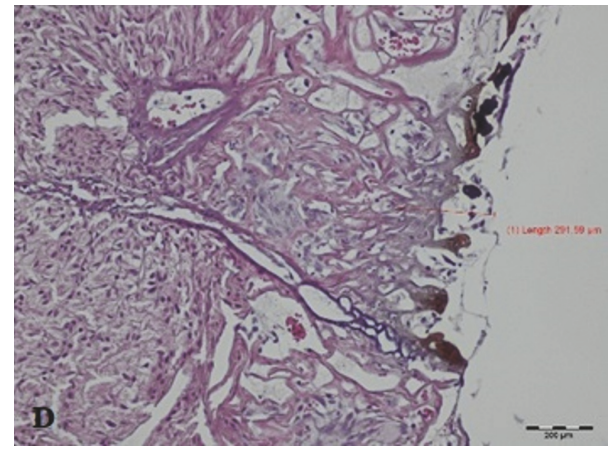

(d)

Figure 3: Histopathological evaluation of the liver tissue damage on day 7 after cutting with thulium laser (magnification $x 40$, HE staining). (a) and (b) Total depth of thermal tissue damage; (c) focal necrotic lesions; (d) clear zone of carbonization in the middle of the incision wound.

inflammatory cells were seen. The width of the changes in the liver tissue produced by the Tm:fiber laser was the largest 7 days after surgery (Figure 3).

In the samples taken 14 days after surgery both zones merged and formed a layer of isolated areas of laser activity filled with the granulation tissue and the residues of carbonized tissue. These areas were surrounded by granulocytes mostly neutrophils, by macrophages, lymphocytes, plasmatic cells, and mesenchymal cells. In T2 group the total width of changed tissue decreased comparing with samples taken 7 days after surgery (Figure 4).

\section{Discussion}

Liver resection remains a surgery not without complications, of which a blood loss is the most serious concern. Different methods of vascular occlusion are applied, and new techniques and devices for parenchymal transection are sought to minimize bleeding. Among others cavitron ultrasonic surgical aspirator, ultrasonic shears, and radiofrequency dissecting sealer are the devices designed to cut liver parenchyma with minimal bleeding [16]. 


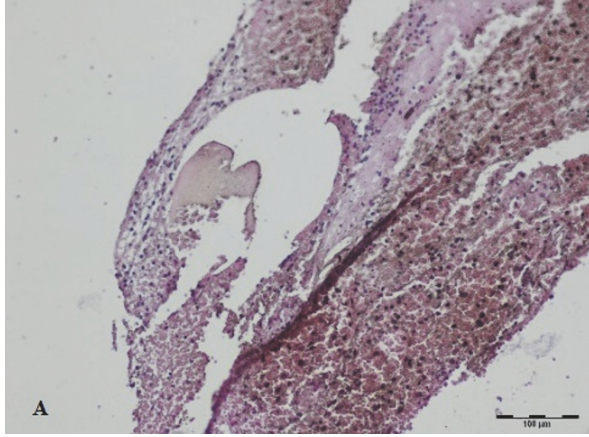

(a)

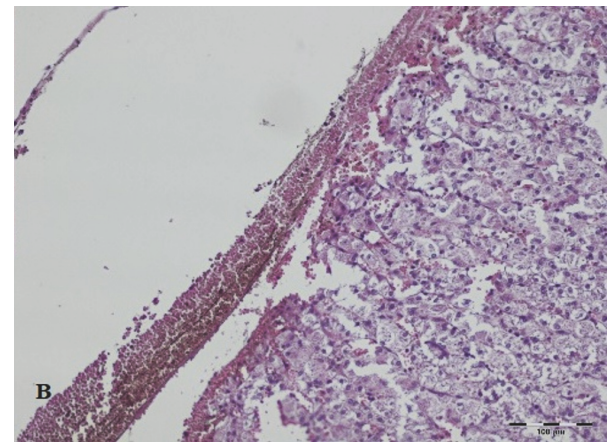

(b)

FIGURE 4: Histopathological evaluation of the liver tissue at the site of transection with thulium laser on day 14 ((a) and (b) magnification x100, HE staining).

In the middle 80s of XX century different types of lasers were tested for their feasibility in liver surgery. Most attention was turned to Nd:YAG lasers and $\mathrm{CO}_{2}$ lasers. Na:YAG laser was compared with ultrasonic surgical aspirator and blunt dissection in a dog model of liver resection. It was not superior to the other two techniques in particular due to a large zone of thermal damage [17]. In a pig model of liver resection Nd:YAG laser, $\mathrm{CO}_{2}$ laser and a combination of these two were tested. $\mathrm{CO}_{2}$ laser had a better cutting efficiency and produced a narrow thermal damage zone approximately $1.5 \mathrm{~mm}$ wide, but it did not provide hemostasis. Na:YAG laser was characterized by a good hemostatic control; however, it produced a broad zone of thermal damage in the cutting margin, from 2.4 to $5.8 \mathrm{~mm}$ depending on the mode of the laser and power used [18]. Although the combination of both lasers gave better effects, neither of these types of lasers was superior to nonlaser techniques of hepatic parenchyma transection, and thus the laser technique had not been transposed to a clinical practice. Later two Nd:YAG lasers (1064 and $1318 \mathrm{~nm}$ ) were studied in a porcine model of laparoscopic liver surgery. The use of $60 \mathrm{~W}$ output energy provided a coagulation of blood vessels up to $2 \mathrm{~mm}$ in diameter and produced a total lateral damage zone of $4.0 \mathrm{~mm}$, what was comparable with earlier studies $[19,20]$. In ex vivo studies a $120 \mathrm{~W}$ Nd:YAG laser produced in pig liver parenchyma a coagulation zone of approximately $255.9 \pm 1.6$ to $375.6 \pm 2.3 \mu \mathrm{m}$, which is comparable to our results in specimens taken intraoperatively. However, the different experimental conditions, inter alia the lack of organ perfusion in ex vivo model may be a limitation in a direct comparison of these two types of lasers [21]. Currently, Nd:YAG lasers have another application in oncotic liver surgery, namely, laser-induced thermotherapy (LITT). In LITT, a low power laser energy produces a well-defined area of coagulative necrosis, thus enabling neoplastic cells damage in situ. Nd:YAG laser with diffusing applicator due to its wavelength of $1046 \mathrm{~nm}$ penetrates the surrounding tissue producing immediate and delayed thermal damage, which makes it feasible for treatment of small tumors not suitable for surgical resection [22].

Thulium doped fiber lasers are promising devices in surgery due to several favorable features. Firstly, they operate at a wavelength of approximately 1940-2000 nm, which corresponds to the length of light highly absorbed by water. Most of the soft tissues is characterized by an abundance of water, and similarly, porcine liver has been shown to have a maximum absorption coefficient at $1940 \mathrm{~nm}$ [23]. This $\mathrm{Tm}$ :fiber laser property results in a shallow penetration of the laser energy into the tissue, followed by a strong local thermal effect without damaging the deeper structures. Moreover, it provides a better cutting precision. In our study Tm:fiber laser had very good cutting properties while the total depth of thermal changes in the liver tissue was from 0.62 to $1.82 \mathrm{~mm}$ depending on the time of evaluation. Similar width of the thermal damage zone (less than $2.0 \mathrm{~mm}$ ) was reported in an experimental pig model of partial nephrectomy with Tm:fiber laser. In another pig model of atypical liver resection with Tm:fiber laser emitting a wavelength of $\sim 1.9 \mu \mathrm{m}$ in a contact mode a narrow scar width of approximately $1-2 \mathrm{~mm}$ after 14-16 days was also noted [24, 25]. However, in a pig model of laparoscopic liver resection 11-15 days after surgery the total thermal damage zone exceeded $5 \mathrm{~mm}$ [26]. The differences might be attributed to the higher power used and other operating techniques. Moreover, in this model a time course of histopathological changes and the initial depth of tissue damage were not studied. Laser energy may cause a direct ultrastructural damage subsequently leading to cell death, what manifested as the largest zone of thermal damage 7 days after surgery in our study. Moreover, thermal ablation of prostate with a Tm:fiber laser emitting at $1940-\mathrm{nm}$ in an in vitro model utilizing dog tissues resulted in a 0.5 to $2.0 \mathrm{~mm}$ zone of thermal coagulation, whereas when cutting the bladder wall and ureter the margins of thermal changes did not exceed $1 \mathrm{~mm}$ [27]. A very precise cutting and a narrow margin of thermal damage achieved with Tm:fiber laser allow sparing more healthy tissue, what may be of advantage in oncologic liver surgery.

Another advantageous feature of the Tm:fiber laser is that the potent local thermal effect resulting in its ability to cut is accompanied by coagulation, thus providing hemostasis. Control of blood loss is a common problem in surgery of highly vascularized tissues as kidney, spleen, or liver. As opposed to early studies on $\mathrm{CO}_{2}$ laser in liver resection, 
in which an efficient cutting did not produce hemostasis [18], we proved that Tm:fiber laser is able to provide a good bleeding control during hepatic transection. In our experiment no visible blood loss or very minor bleeding was observed after resection of distal $2 / 3$ of right lateral lobe in swine. Similar results were observed by Theisen-Knude et al. [25] in porcine model of partial liver resection with a $1.9 \mu \mathrm{m}$ thulium laser. An atypical partial hepatectomy by open and laparoscopic techniques did not result in significant bleeding or bile leakage, suggesting feasibility of the Tm:fiber laser in liver surgery $[25,26]$. Moreover, in experimental partial nephrectomy using Tm:fiber laser, good hemostasis was observed [24]. Thulium laser with a wavelength of $2 \mu \mathrm{m}$ has been used for partial nephrectomy in five human patients as well, the control of blood loss was very good, and authors discussed a possibility of performing the procedure without hilar clamping [28]. This thesis was further supported by performing the experimental partial nephrectomy without hilar control conducted in the pig model with thulium YAG laser as well as in human patients undergoing partial nephrectomy for kidney tumors [29, 30]. Moreover, thulium laser technique for prostate enucleation was proved to be an efficient procedure especially in patients with high prostate volumes. It also minimizes blood loss and might be considered the best choice for patients under concurrent antiplatelet therapy $[31,32]$.

\section{Conclusion}

In conclusion Th:fiber laser is efficacious in cutting with a narrow zone of thermal injury and provides good hemostasis during partial liver resection and liver tissue incision. Tm:fiber laser operating at $1940 \mathrm{~nm}$ may be a potential tool in oncologic liver surgery, especially when sparing of a healthy tissue is being a priority and small atypical excisions are performed.

\section{Data Availability}

The data used to support the findings of this study are included within the article.

\section{Conflicts of Interest}

The authors declare that there are no conflicts of interest regarding the publication of this article.

\section{Acknowledgments}

This work was financed by the National Centre for Research and Development (Grant no. INNOTECHK3/IN3/55/225968/NCBR) and by the Wroclaw Center for Biotechnology Program KNOW (National Scientific Leadership Center) for the 2014-2018.

\section{References}

[1] E. Moggia, B. Rouse, C. Simillis et al., "Methods to decrease blood loss during liver resection: a network meta-analysis,"
Cochrane Database of Systematic Reviews, vol. 10, no. CD010683, 2016.

[2] A. Tarasik, J. Jaroszewicz, and M. Januszkiewicz, "Surgical treatment of liver tumors - own experience and literature review," Clinical and Experimental Hepatology, vol. 3, no. 1, pp. $1-8,2017$.

[3] C. Reissfelder, N. N. Rahbari, M. Koch et al., "Postoperative course and clinical significance of biochemical blood tests following hepatic resection," British Journal of Surgery, vol. 98, no. 6, pp. 836-844, 2011.

[4] M. T. de Boer, I. Q. Molenaar, and R. J. Porte, "Impact of blood loss on outcome after liver resection," Digestive Surgery, vol. 24, no. 4, pp. 259-264, 2007.

[5] T. H. Maiman, "Stimulated optical radiation in Ruby," Nature, vol. 187, no. 4736, pp. 493-494, 1960.

[6] N. S. Kapany, N. A. Peppers, H. C. Zweng, and M. Flocks, "Retinal photocoagulation by lasers," Nature, vol. 199, no. 4889, pp. 146-149, 1963.

[7] B. Corcóstegui, S. Durán, M. O. González-Albarrán et al., "Update on Diagnosis and Treatment of Diabetic Retinopathy: A Consensus Guideline of the Working Group of Ocular Health (Spanish Society of Diabetes and Spanish Vitreous and Retina Society)," Journal of Ophthalmology, vol. 2017, 2017.

[8] T. Yilmaz, O. M. Altuntaş, N. Süslü et al., "Total and Partial Laser Arytenoidectomy for Bilateral Vocal Fold Paralysis," BioMed Research International, vol. 2016, 2016.

[9] S. Moretti, M. S. Kaminer, A. Le Pillouer-Prost, and P. Campolmi, "Conventional and unconventional use of lasers in skin disorders," BioMed Research International, vol. 2015, 2015.

[10] W. Jerjes, Z. Hamdoon, and C. Hopper, " $\mathrm{CO}_{2}$ lasers in the management of potentially malignant and malignant oral disorders," Head \& Neck Oncology, vol. 4, no. 1, article 17, 2012.

[11] C. Lagman, L. K. Chung, P. E. Pelargos et al., "Laser neurosurgery: A systematic analysis of magnetic resonance-guided laser interstitial thermal therapies," Journal of Clinical Neuroscience, vol. 36, pp. 20-26, 2017.

[12] C. Netsch and T. Bach, "Vaporization vs. Enucleation techniques for BPO: Do we have a standard?" Current Opinion in Urology, vol. 25, no. 1, pp. 45-52, 2015.

[13] H. Z. Alagha and M. Gülsoy, "Photothermal ablation of liver tissue with 1940-nm thulium fiber laser: An ex vivo study on lamb liver," Journal of Biomedical Optics, vol. 21, no. 1, 2016.

[14] M. Michalska, W. Brojek, Z. Rybak, P. Sznelewski, M. Mamajek, and J. Swiderski, "Highly stable, efficient Tm-doped fiber laser - A potential scalpel for low invasive surgery," Laser Physics Letters, vol. 13, no. 11, 2016.

[15] A. H. Fischer, K. A. Jacobson, J. Rose, and R. Zeller, "Hematoxylin and eosin staining of tissue and cell sections," Cold Spring Harbor Protocols, vol. 2008, no. 5, 2008.

[16] C. Simillis, T. Li, J. Vaughan, L. A. Becker, B. R. Davidson, and K. S. Gurusamy, "A Cochrane systematic review and network meta-analysis comparing treatment strategies aiming to decrease blood loss during liver resection," International Journal of Surgery, vol. 23, pp. 128-136, 2015.

[17] K.-G. Tranberg, P. Rigotti, K. A. Brackett, H. S. Bjornson, J. E. Fischer, and S. N. Joffe, "A comparison using the Nd-YAG laser, an ultrasonic surgical aspirator, or blunt dissection," The American Journal of Surgery, vol. 151, no. 3, pp. 368-373, 1986.

[18] H. -. Meyer and K. Haverkampf, "Experimental study of partial liver resection with a combined CO2 and Nd:YAG laser," Lasers in Surgery and Medicine, vol. 2, no. 2, pp. 149-154, 1982. 
[19] S. S. Chopra, G. Wiltberger, U. Teichgraeber et al., "Evaluation of laparoscopic liver resection with two different Nd:YAG lasers for future use in a high-field open MRI," Photomedicine and Laser Surgery, vol. 27, no. 2, pp. 281-286, 2009.

[20] S. S. Chopra, S. C. Schmidt, G. Wiltberger, U. Teichgräber, and G. Schumacher, "Establishing Nd:YAG laser-based left lateral liver resection: Comparison of open, laparoscopic, and handassisted approach in a porcine model," Surgical Laparoscopy Endoscopy \& Percutaneous Techniques, vol. 20, no. 2, pp. 73-78, 2010.

[21] A. Kirschbaum, P. Rexin, D. K. Bartsch, and P. Di Fazio, "The Nd:YAG LIMAX ${ }^{\circledR} 120$ high-output laser: Local effects and resection capacity on liver parenchyma," Lasers in Medical Science, vol. 29, no. 4, pp. 1411-1416, 2014.

[22] K. Eichler, S. Zangos, T. Gruber-Rouh, T. J. Vogl, and M. G. MacK, "Magnetic resonance-guided laser-induced thermotherapy in patients with oligonodular hepatocellular carcinoma: Long-term results over a 15-year period," Journal of Clinical Gastroenterology, vol. 46, no. 9, pp. 796-801, 2012.

[23] J. P. Ritz, A. Roggan, C. Isbert, G. Mller, H. J. Buhr, and C. T. Germer, "Optical properties of native and coagulated porcine liver tissue between 400 and $2400 \mathrm{~nm}$," Lasers in Surgery and Medicine, vol. 29, no. 3, pp. 205-212, 2001.

[24] D. Theisen-Kunde, S. Tedsen, C. Doehn, D. Jocham, and I. K. Von Schmeling, "Comparison between a 1.92- $\mu \mathrm{m}$ fiber laser and a standard HF-dissection device for nephron-sparing kidney resection in a porcine in vivo study," Lasers in Medical Science, vol. 26, no. 4, pp. 509-514, 2011.

[25] D. Theisen-Kunde, H. Wolken, V. Danicke, R. Brinkmann, H. Bruch, and M. Kleemann, "In vivo study of partial liver resection on pigs using a $1.9 \mu \mathrm{m}$ Thulium fiber laser," in Proceedings of the European Conference on Biomedical Optics, p. 809211, Munich, 2011.

[26] D. B. Ellebrecht, D. Theisen-Kunde, C. Kuempers, T. Keck, M. Kleemann, and H. Wolken, "Analysis of laparoscopic laser liver resection in standardized porcine model," Surgical Endoscopy, pp. 1-7, 2018.

[27] N. M. Fried and K. E. Murray, "High-power thulium fiber laser ablation of urinary tissues at $1.94 \mu \mathrm{m}$," Journal of Endourology, vol. 19, no. 1, pp. 25-31, 2005.

[28] T. Gruschwitz, J. Schubert, and H. Wunderlich, "Lasersupported partial nephrectomy for renal cell carcinoma," Urologe - Ausgabe A, vol. 47, no. 9, pp. 1173-1174, 2008.

[29] T. Y. Hsueh, A. W. Chiu, A. C. Huang et al., "Thulium laser laparoscopic partial nephrectomy without renal hilar control in a porcine model," Urological Science, vol. 21, no. 3, pp. 126-131, 2010.

[30] I. Kyriazis, M. Ozsoy, P. Kallidonis, V. Panagopoulos, M. Vasilas, and E. Liatsikos, "Current evidence on lasers in laparoscopy: partial nephrectomy," World Journal of Urology, vol. 33, no. 4, pp. 589-594, 2015.

[31] S. Rausch, T. Heider, J. Bedke et al., "Analysis of early morbidity and functional outcome of thulium: Yttrium-aluminum-garnet laser enucleation for benign prostate enlargement: Patient age and prostate size determine adverse surgical outcome," Urology, vol. 85, no. 1, pp. 182-188, 2015.

[32] F. Iacono, D. Prezioso, G. Di Lauro et al., "Efficacy and safety profile of a novel technique, ThuLEP (Thulium laser enucleation of the prostate) for the treatment of benign prostate hypertrophy. Our experience on 148 patients," BMC Surgery, vol. 12, no. 1, article no. S21, 2012. 


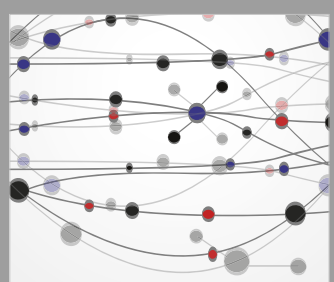

The Scientific World Journal
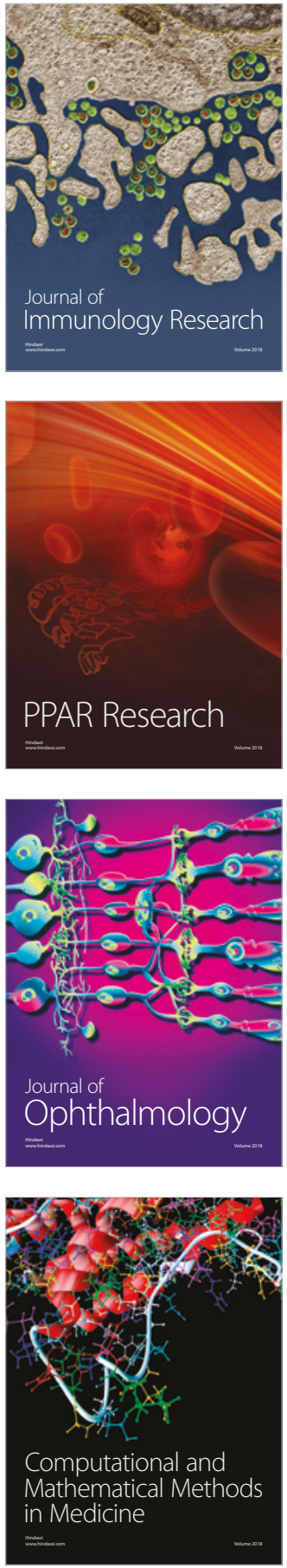

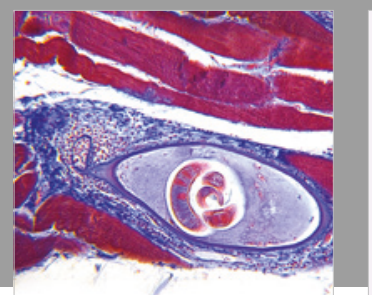

Gastroenterology Research and Practice

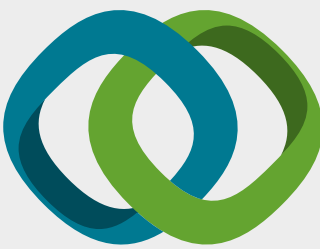

\section{Hindawi}

Submit your manuscripts at

www.hindawi.com
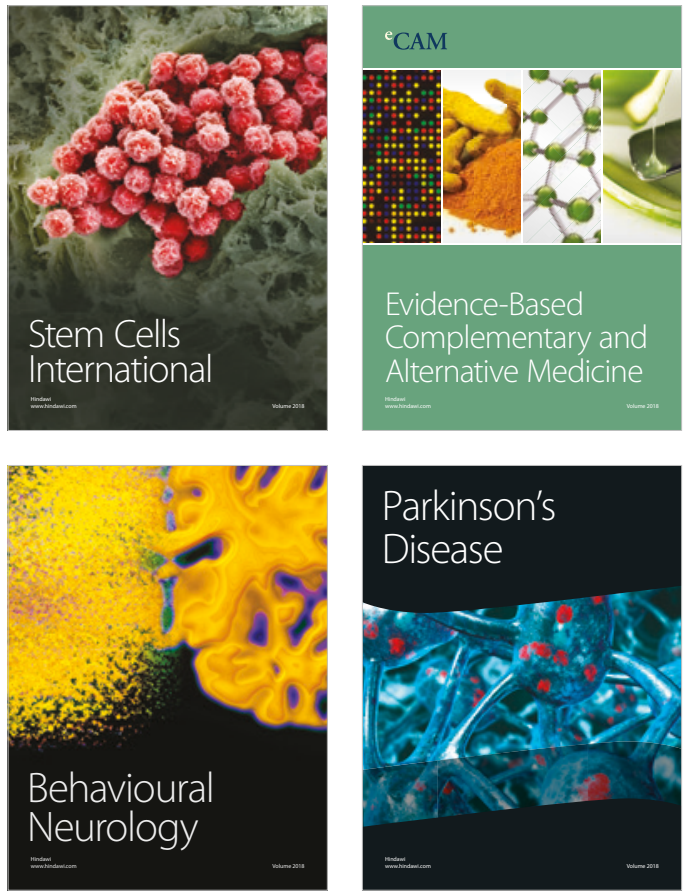

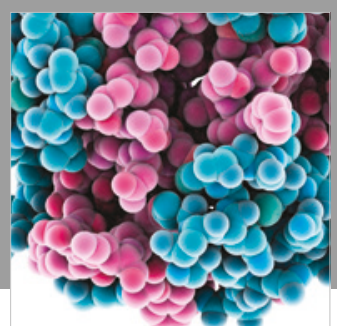

ournal of

Diabetes Research

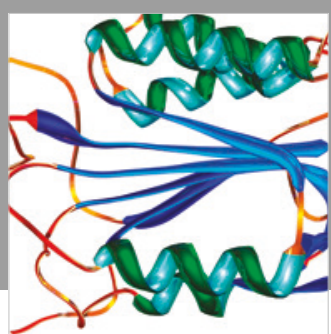

Disease Markers
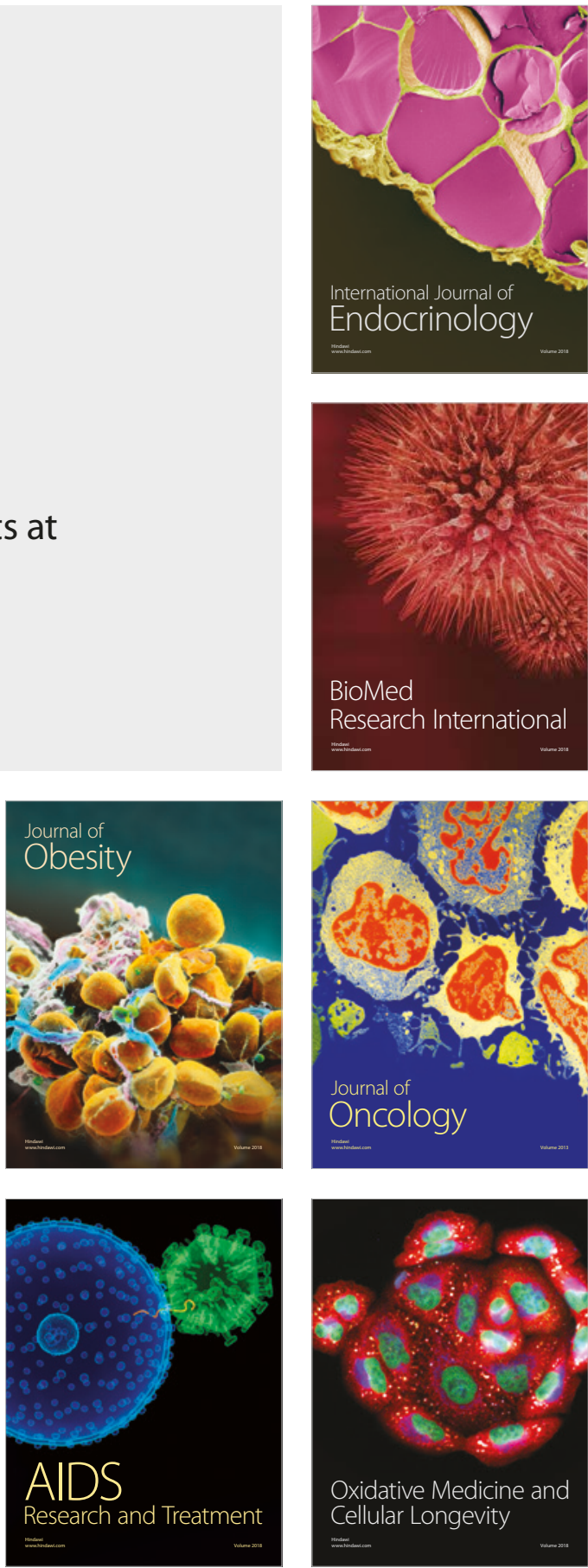